\title{
TGF- $\beta$-mediated airway tolerance to allergens induced by peptide-based immunomodulatory mucosal vaccination
}

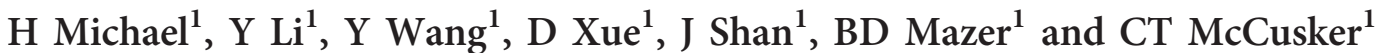

We sought to modulate mucosal immune responses using neonatal vaccination to avert the development of allergic airways disease (AAD). Pulmonary pathology in AAD is driven by Thelper (TH)2 cytokines, in particular interleukin (IL)4 and IL13, the expression and actions of which are regulated by the transcription factor STAT6. We developed a peptide homolog of STAT6, STAT6-IP. Neonatal mice given, intranasally, STAT6-IP, in an effort to modulate de novo airways immune responses, developed tolerance following subsequent allergen sensitization, with either ovalbumin or ragweed allergens, as demonstrated by reduced TH2 cytokines and specific immunoglobulin (lg)E and the significant increases in the latency-associated peptide (LAP) ${ }^{+}$T-regulatory (Treg) cell subset and expression of transforming growth factor (TGF)- $\beta$. This regulatory phenotype was transferrable by CD4 ${ }^{+} \mathrm{T}_{\text {cells }}$ or CD11c ${ }^{+}$dendritic cells (DCs) derived from STAT6-IP-vaccinated mice. Anti-TGF- $\beta$ treatment during allergen sensitization, however, re-established the pro-inflammatory TH2 response. Thus, neonatal STAT6-IP vaccination induces prospective TGF- $\beta$-dependent tolerance to allergen and constitutes a novel highly effective immunomodulatory allergy prevention strategy.

\section{INTRODUCTION}

Epidemiological studies have suggested that early environmental stimuli can modulate mucosal immune responses resulting in decreased lifetime risk of development of allergic airways disease (AAD) ${ }^{1-3}$ Strategies developed for primary prevention, such as allergen avoidance, however, have been largely unsuccessful. ${ }^{4-7}$ Effective prevention and treatment therapies ideally would target the regulatory pathways of airway mucosal immune responses to promote airways tolerance to allergen. ${ }^{3,8-10}$

Induction of the allergic phenotype, beginning in childhood, involves the differentiation of allergen-specific $\mathrm{T}$ cells into cells of the $\mathrm{T}$ helper $(\mathrm{TH}) 2$ phenotype and may result from a failure to appropriately polarize $\mathrm{T}$ cells to tolerant immune responses. ${ }^{11,12}$ Thus, when a novel allergen enters the system, there is a preferential development of $\mathrm{TH} 2$ cells. Activated $\mathrm{TH} 2$ cells promote inflammation through release of interleukin (IL) 4 and IL5, airway hyperresponsiveness (AHR), and remodeling through IL4 and IL13 as well as B-cell class switch to immunoglobulin (Ig)E. ${ }^{12-14}$ Polarization to TH2 relies on the elaboration of IL4 by cells in the local milieu at the time of allergen presentation by antigen-presenting cells such as dendritic cells (DCs). ${ }^{10,12,15,16}$ IL4 and IL13 share a common receptor subunit, and binding of these cytokines to their cognate receptor results in recruitment and tyrosine phosphorylation of the STAT6 transcription factor. ${ }^{17}$ Homodimers of activated STAT6 translocate to the nucleus where they regulate transcription of IL4/IL13-dependent gene expression. ${ }^{18-20}$ Interventions targeting TH2 cytokines IL4 or IL13 have blunted some but not all features of AAD. ${ }^{21-23}$ In an effort to target both IL4 and IL13, we developed a cell penetrating, chimeric inhibitory peptide, STAT6-IP, that inhibits antigeninduced $\mathrm{TH} 2$ cytokine production and abrogates allergeninduced airways hyperresponsiveness and inflammation in experimental models of allergic asthma. ${ }^{24,25}$ Given that a predisposition to induction of $\mathrm{TH} 2$ responses is postulated to lead to allergic disease if not influenced toward tolerance, we wanted to determine whether early in life vaccination with STAT6-IP would predispose to tolerance in the event of subsequent allergen exposure.

${ }^{1}$ Meakins-Christie Laboratories, McGill University and the MUHCRI, Montreal, Quebec, Canada. Correspondence: CT McCusker (Christine.mccusker@mcgill.ca) Received 22 May 2014; accepted 30 January 2015; published online 18 March 2015. doi:10.1038/mi.2015.15 
Fetal and neonatal immune responses differ significantly from older children and adults. Both the innate and adaptive systems are relatively compromised in neonates. There are increased numbers of naive $\mathrm{T}$ and $\mathrm{B}$ cells with poor production of proinflammatory cytokines. ${ }^{26}$ The innate system also shows reduced responsiveness to toll-like receptor agonists in neonates and toll-like receptor-mediated polarizing TH1-type responses are impaired. ${ }^{27}$ Early in the neonatal period, immature DCs, which originate in the bone marrow, migrate to the airways and mature under the influence of the local lung environment. ${ }^{10}$ Mucosal exposures to complex antigenic environments lead to maturation of tolerogenic DCs, whereas reduced or absent microbial exposures result in the maintenance of a default TH2-skewed immune response., ${ }^{8,10,28}$ Tolerogenic DCs may induce the development of T-cell tolerance through a variety of mechanisms including production of cytokines such as IL10 and transforming growth factor (TGF)- $\beta$ as well as inhibition of T-cell proliferation and cytokine expression and via production of indolamine 2,3-dioxygenase (IDO) ${ }^{29}$ Our data have demonstrated, in murine models, that early in life, mucosal exposure to lipopolysaccharide promotes airways tolerance to allergens through upregulation of Treg cells. ${ }^{30}$ Other studies have shown that maternal allergen exposure during lactation leads to passage of allergenic proteins into the breast milk and with the concomitant presence of TGF- $\beta$ in the milk results in induction of allergen-specific tolerance in the pups. ${ }^{31,32}$ These data suggest that early mucosal stimuli direct $\mathrm{T}$-cell maturation towards the tolerance pathway effectively preventing development of allergy.

On the basis of these observations, we postulated that inhibition of TH2-mediated cell activation, during a critical development window in neonates, would promote programming of immune tolerance to novel allergens and prevent allergy development. To test our hypothesis in the present study, we vaccinated neonatal mice with STAT6-IP and examined subsequent de novo mucosal immune responses to allergen. We show for the first time that vaccination of neonatal mice with STAT6-IP results in sustained tolerance to allergen and prevents induction of AAD. We further show that this tolerant phenotype is dependent upon TGF- $\beta$ and that tolerance can be transferred to naïve mice via $\mathrm{CD} 4^{+} \mathrm{T}$ cells or CD11c ${ }^{+}$DC. These "tolerogenic" DCs have increased expression of IDO, and the inhibition of IDO activity results in a significant decrease in induced TGF- $\beta$ in cultured cells. Finally, we demonstrate that T cells from STAT6-IP mice suppress proliferation of allergen-sensitized $\mathrm{T}$ cells in vitro. Thus, mucosal vaccination using STAT6-IP has the potential for primary allergy and asthma prevention through the promotion of active airways tolerance to allergen.

\section{RESULTS}

STAT6-IP vaccination in neonatal airways prevents experimental AAD

STAT6-IP (IP) or a negative control peptide (STAT6-CP or CP) were instilled daily in the nares of awake 3-8-day-old mice. The
STAT6-IP differs from the STAT6-CP by only one amino acid. The STAT6-IP contains a phosphotyrosine residue, which has been replaced by phenylalanine in STAT6-CP. ${ }^{24}$ At 6 weeks of life, vaccinated animals were sensitized and challenged to ovalbumin (OVA) (Figure 1a). We have previously demonstrated robust inflammation and airways hyperresponsiveness associated with increases in $\mathrm{TH} 2$ cytokines and allergenspecific IgE is achieved using this sensitization and challenge protocol. ${ }^{24,33}$ Animals vaccinated with the $\mathrm{CP}$ developed robust airway inflammation and AAD similar to the sham vaccinated allergic group (OVA) following OVA challenge, whereas, in contrast, IP-vaccinated mice (IP) showed little or no inflammatory response under the same conditions (Figure $\mathbf{1 b}$ and $\mathbf{c}$ ). Indeed, the profile of inflammatory cells in the bronchoalveolar lavage fluid from IP-vaccinated animals did not significantly differ from that of phosphate-buffered saline (PBS)-only exposed (allergen-naïve) mice (Figure 1b). OVA-induced mucous production (Figure 1c) and peribronchial inflammation (Supplementary Figure S1a online) were markedly increased in the in OVA and CP groups, consistent with the increased levels of mRNA encoding Muc-2/Muc 5ac and CCL11 (eotaxin1) in whole-lung homogenates (Supplementary Figure S1d). In contrast, for IP-vaccinated animals, these inflammatory parameters were similar to allergen-naïve (PBS). Importantly, in IP-vaccinated mice, methacholine-induced lung resistance also did not differ from that of the naive mice (Figure 1f), whereas there were significant increases in both the OVA and $\mathrm{CP}$ allergic groups. There was also an increased frequency of latency-associated peptide (LAP) ${ }^{+}$, $\mathrm{CD} 4{ }^{+} \mathrm{T}$ cells, a phenotype associated with inducible Foxp3 ${ }^{-}$ regulatory $\mathrm{T}$ cells, in whole-lung homogenates from IPvaccinated mice (Figures 1d and e, Supplementary Figure S1c). ${ }^{34}$ Finally, serum OVA-specific IgE levels were significantly increased in CP-vaccinated and OVA groups, whereas IP-vaccinated mice had barely detectable allergen-specific IgE (Figure 1g).Taken altogether, these data suggest that neonatal STAT6-IP vaccination prevents inflammatory airway immune responses to OVA and the formation of AAD in adult mice.

To demonstrate that the asthma-protective effect of neonatal STAT6-IP vaccination was not limited to only the OVA model, vaccinated animals underwent prolonged sensitization with ragweed (RW) (Figure 1h). With the extended period of repeated sensitization, these mice develop more pronounced airways hyperresponsiveness and inflammation in comparison with the OVA model. ${ }^{25}$ Nevertheless, consistent with the findings of the OVA model, STAT6-IP-vaccinated mice showed minimal inflammation and limited hyperresponsiveness to methacholine following RW challenge (Figures 1i-k), whereas, under the same conditions, the STAT6-CP-vaccinated and the sham-vaccinated RW allergic groups showed robust inflammation and airways hyperresponsiveness (Figures 1i-k and Supplementary Figure S1b). RW-specific IgE formation (Figure 11) was elevated in CP and RW groups but IPvaccinated mice developed only minimal levels. These data demonstrate that neonatal STAT6-IP vaccination results in protection from the development of allergic asthma in both 
acute and chronic models of AAD and the STAT6-IP-mediated effects are not restricted to a particular allergen.

\section{Distinctive cytokine recall-response profiles in splenocytes of STAT6-IP-vaccinated mice}

To evaluate the effects of STAT6-IP vaccination on recall immune responses, splenocytes, derived from vaccinated allergen-sensitized and-challenged mice, were cultured in vitro in the presence of allergen, and cytokine profiles were assessed. As expected, cultures from OVA and RWallergic and CP-vaccinated mice showed increased levels of IL4 and IL13 (Figures 2a,b,d and e), whereas, in contrast, splenocytes from IP-vaccinated mice showed lower production of TH2 cytokines after culture with OVA (Figures 2a and b) or RW (Figures 2d and e) with significantly higher levels of TGF- $\beta$ (Figures $\mathbf{2 c - f}$ ). Interestingly, IL10 and interferon a

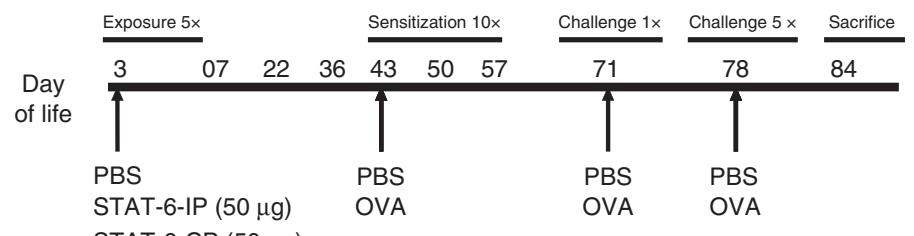

STAT-6-CP $(50 \mu \mathrm{g})$

C

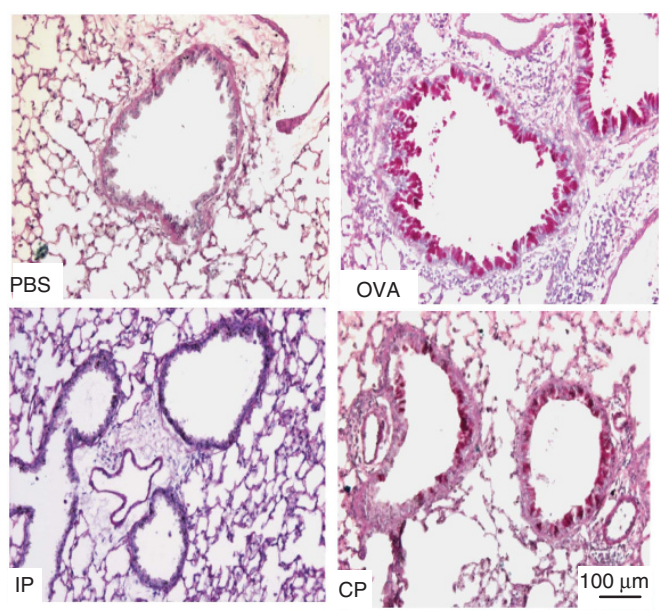

b

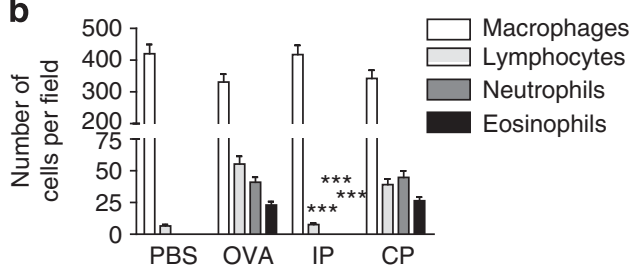

d

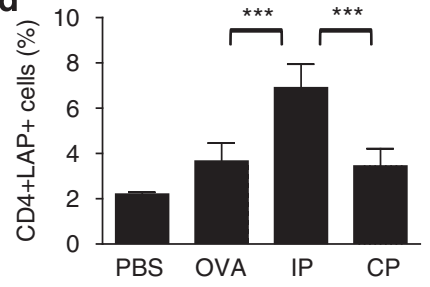

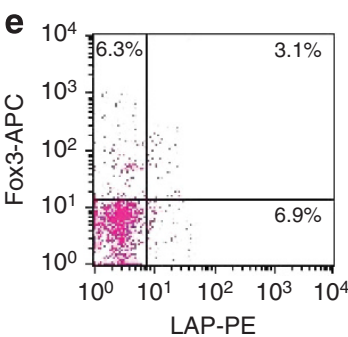

f

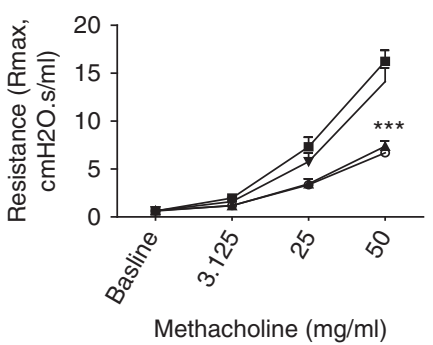

g

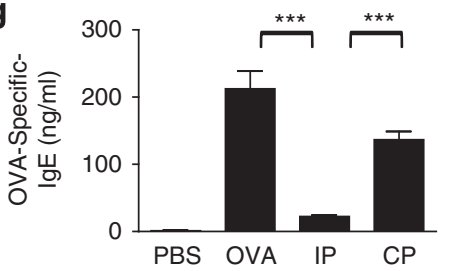

Figure 1 Vaccination with STAT6-IP prevents allergic sensitization and allergic airways disease. (a) Beginning at 3 days of life, mice were vaccinated five times with STAT-6-IP (IP), STAT-6-CP (CP) or PBS by intranasal application, and at the age of 6 weeks, they were sensitized and challenged with OVA or PBS. Animals receiving PBS only served as the non-allergic controls (PBS) and those sham-vaccinated with PBS then sensitized with OVA were considered allergic (OVA) mice. ${ }^{24}$ (b) Differential cell counts were obtained from recovered BAL fluid and stained with Diff-Quick. White columns denote macrophages ( $\square$ ), lymphocytes ( $(\square)$ light grey, neutrophils ( $\square$ ) dark grey, and eosinophils ( $\mathbf{a}$ ) black. (c) Lung sections were stained with Periodic Acid Schiff stain and mucus-positive cells were identified (original magnification $\times 100$ ). (d) Percentage of $\mathrm{LAP}^{+} \mathrm{CD}^{+}{ }^{+} \mathrm{T}_{\text {cells }}$ in whole lung homogenates assessed by flow cytometry and (e) frequency of LAP vs. FoxP3 in $\mathrm{CD} 4{ }^{+}$cells from whole-lung homogenates. (f) Bronchial airway hyperresponsiveness to methacholine following challenge with PBS or OVA was assessed using the Flexivent small animal ventilator. PBS (-) circle, OVA ( $\mathbf{\square})$ square, IPvaccinated $(\boldsymbol{\Lambda})$ upright triangle, and CP-vaccinated $(\boldsymbol{\nabla})$ point-down triangle, respectively. (g) OVA-specific-lgE was quantified in serum samples by ELISA. (h) Animals vaccinated as described in a above were sensitized and challenged with PBS or RW as depicted using the chronic sensitization protocol. ${ }^{25}$ Mice sensitized and challenged with PBS were non-allergic (PBS) and those with RW considered allergic (RW), whereas animals vaccinated with STAT-6-IP (IP) or STAT-6-CP (CP) were assessed following RW sensitization and challenge. (i) Differential cell counts from BAL were assessed as described in b above. White columns denote macrophages ( $\square$ ), lymphocytes ( $\square$ ) light grey, neutrophils ( $\square$ ) dark grey, and eosinophils ( $\square$ ) black. (j) Lung sections were stained with Periodic Acid Schiff stain and mucus-positive cells were identified (original magnification $\times 100)$. (k) Bronchial airway hyperresponsiveness to methacholine following challenge with PBS or RW was assessed using the Flexivent small animal ventilator. PBS ( $)$ ), RW ( $\mathbf{\square})$, IP-vaccinated $(\boldsymbol{\Delta})$, and CP-vaccinated $(\boldsymbol{\nabla})$, respectively. (I) RW-specific IgE in serum samples by ELISA. ${ }^{* \star} P<0.001$. For each experimental group, there was a minimum of 6-8 animals per group and experiments were replicated two to three times to assure reproducibility. BAL, bronchoalveolar lavage; CP, control peptide; Ig, immunoglobulin; LAP, latency-associated peptide; OVA, ovalbumin; PBS, phosphate-buffered saline; RW, ragweed. 


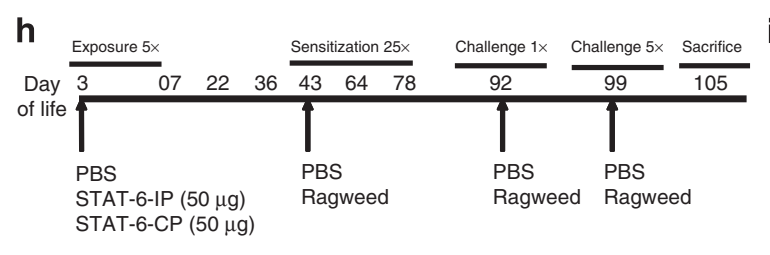

j

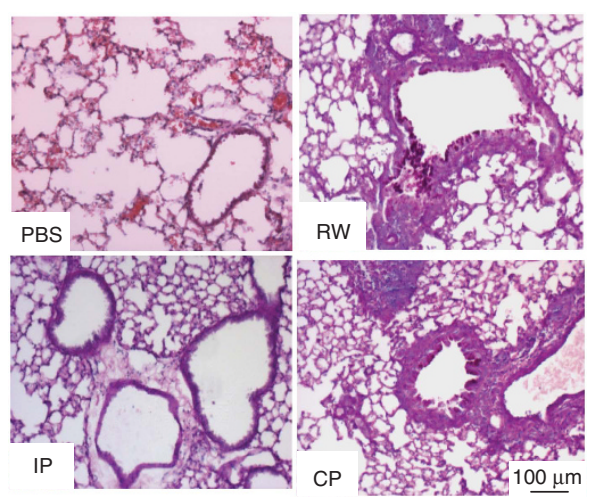

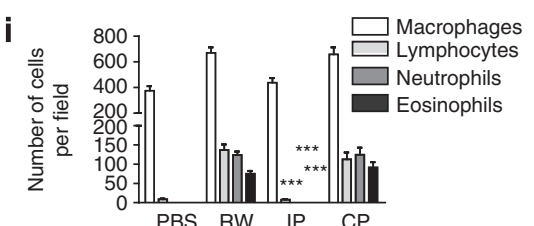

k

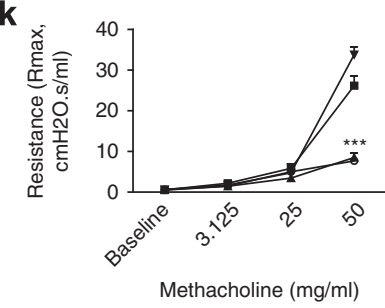

I

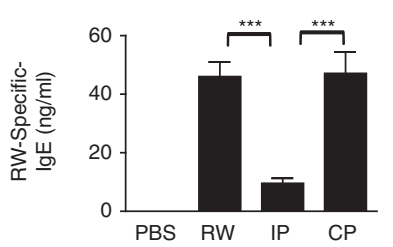

Figure 1 Continued.

(IFN)- $\gamma$ levels were also lower in splenocytes derived from IP-vaccinated mice demonstrating a profile of suppression of multiple cytokines (Supplementary Figure S2a-d). Collectively, these data show that splenocytes derived from IPvaccinated mice produce significantly high amounts of TGF- $\beta$ post-allergen challenge, whereas the levels of $\mathrm{TH} 2$ cytokines such as IL4 or IL13 are very low. These data suggest that STAT6-IP vaccination results in the development of tolerant immune responses, with increased expression of TGF- $\beta$, associated with a general reduction in $\mathrm{TH} 1$ and $\mathrm{TH} 2$ cytokine production.

\section{STAT6-IP vaccine modulates cytokine expression: Contribution of $\mathrm{CD}^{+}{ }^{+} \mathrm{T}$ cells}

Splenocyte $\mathrm{CD}^{+}{ }^{+} \mathrm{T}$ cells from IP or CP-vaccinated mice, isolated by magnetic cell selection as described in the methods, were cocultured with $\mathrm{CD} 4{ }^{+}$T-cell-depleted splenocytes from OVA-allergic mice to determine the role of IP-derived $\mathrm{CD} 4{ }^{+}$ $\mathrm{T}$ cells in the observed modulation of cytokines. After culture with OVA, cytokine levels in supernatants were analyzed (Figures 2g-i, Supplementary Figure S3a-c, Supplementary Figure S4a,b). IL4 (Figure 2g), IL13 (Figure 2h) as well as IL10 and IFN- $\gamma$ (Supplementary Figure S4a,b) levels were significantly lower in cocultures containing $\mathrm{CD} 4{ }^{+} \mathrm{T}$ cells from IP-vaccinated mice (IP-T cells) when compared with those with $\mathrm{T}$ cells from $\mathrm{CP}$-vaccinated mice (CP-T cells) when cultured with CD4-depleted splenocytes from OVA-allergic mice. TGF- $\beta$ (Figure 2i) levels were specifically elevated in cocultures with STAT6-IP derived OVA-sensitized T cells. Cocultures with $\mathrm{T}$ cells from IP-vaccinated allergen-naïve mice also had increased TGF- $\beta$ levels if cocultured with OVAallergic splenocytes (Supplementary Figure S3c). Together, these data suggest that IP-T cells have immunomodulatory activity in vitro.

\section{STAT6-IP vaccine modulates cytokine expression: Contribution of $\mathrm{CD}_{11 \mathrm{c}^{+}} \mathrm{DCs}$}

We reasoned that the effect of neonatal STAT6-IP vaccination was not acting directly on the $\mathrm{T}$ cell but rather influencing the milieu of the mucosal immune response. DC-T cell synapses are essential steps in the developing immune response. Thus, we assessed cytokine production in cocultures of splenocyte $\mathrm{CD}_{11 \mathrm{c}^{+}} \mathrm{DCs}$, isolated from either IP-vaccinated (IP-DC) or CP-vaccinated (CP-DC), OVA-sensitized and challenged animals, and DC-depleted splenocytes from OVA-allergic (OVA) mice. When incubated with DC-depleted splenocytes from OVA-allergic mice, production of IL4 (Figure $2 \mathbf{j}$ ) and IL13 (Figure 2k) as well as IL10 and IFN- $\gamma$ (Supplementary Figures S4c and d) were significantly lower in cocultures in IP-DC cocultures compared with CP-DC cocultures. Consistent with the coculture experiments with IP-T cells (Figure 2i), cocultures containing IP-DCs also produced greater amounts of TGF- $\beta$ whether derived from OVA-sensitized or naïve (PBS) cultured mice (Figure 2l, Supplementary Figure S3f). Thus, $\mathrm{CD}_{11 \mathrm{c}^{+}}$DCs from IP-vaccinated mice differentially regulate cytokine production in allergen-stimulated cultures with elaboration of regulatory cytokines and not $\mathrm{TH} 2$ cytokines.

\section{Inhibitory phenotype is adoptively transferred via CD4 ${ }^{+}$ T cells.}

We next determined whether $\mathrm{CD}^{+}{ }^{+} \mathrm{T}$ cells from neonatal STAT-6-IP-vaccinated mice could mediate the AAD-protective effect in vaccine-naïve mice. $\mathrm{CD} 4^{+} \mathrm{T}$ cells from IP- or $\mathrm{CP}$ - vaccinated DO11.10 mice were isolated and adoptively 
a

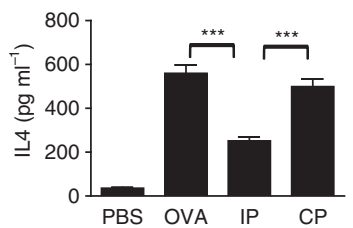

d

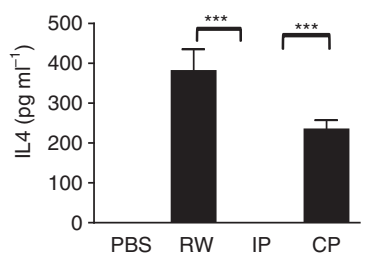

g

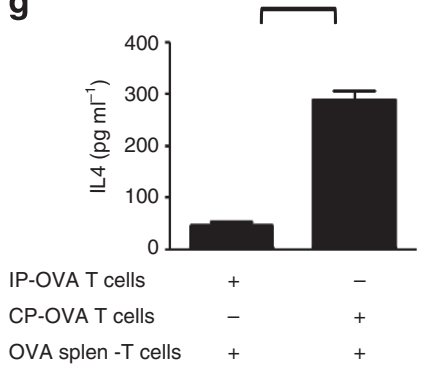

j

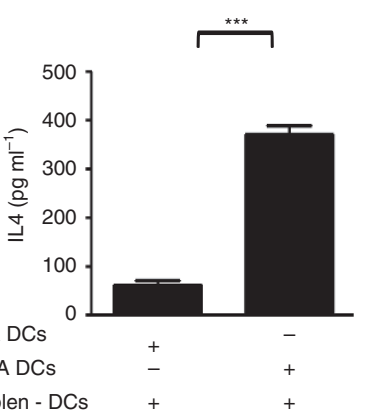

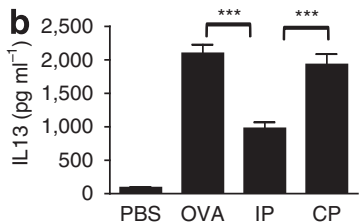
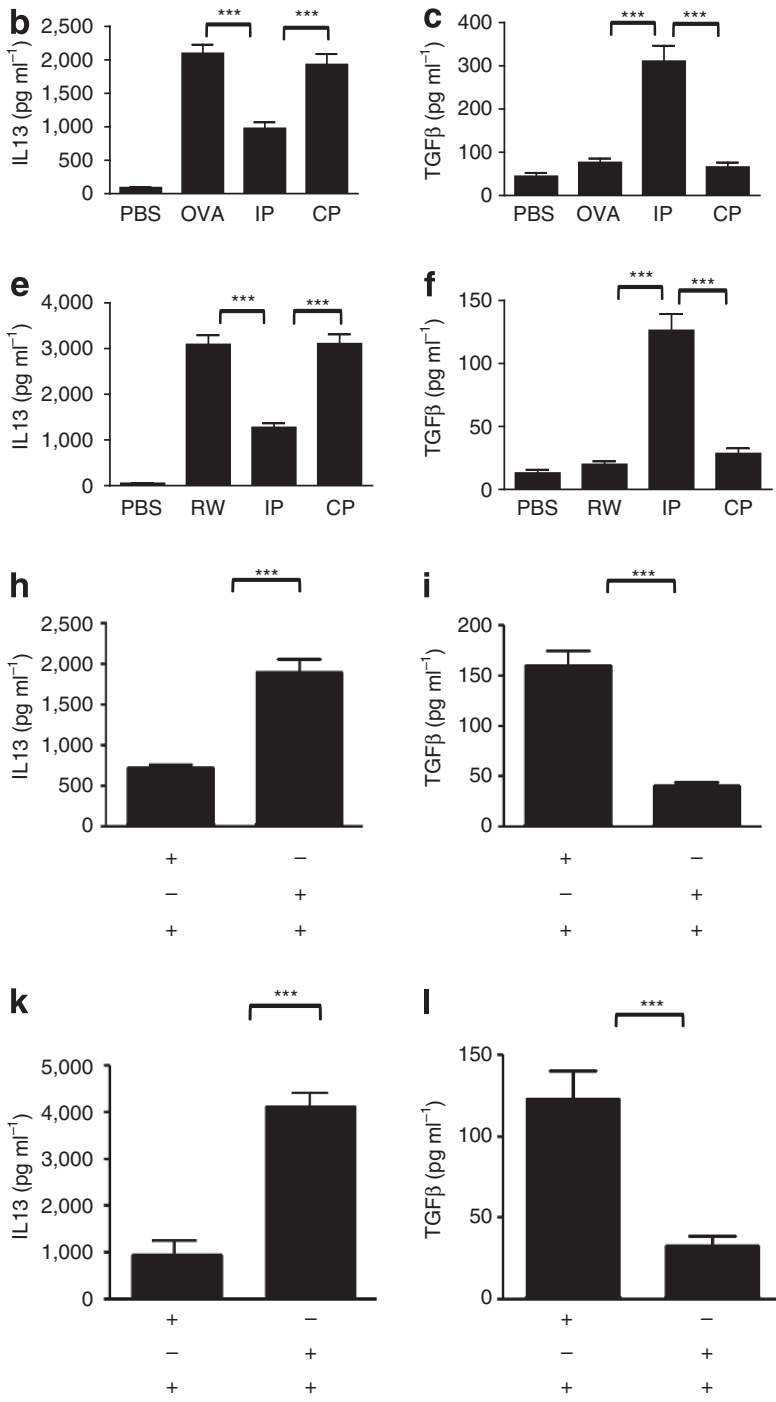

Figure 2 TH2 cytokine expression is lower in cultured splenocytes from STAT6-IP vaccinated mice while TGF- $\beta$ level are elevated in vitro and coculture of T cells or DCs from STAT6-IP vaccinated animals with T-cell- or DC-depleted splenocytes from naïve or OVA-allergic mice modulates cytokine expression. Splenocytes from STAT6-IP, -CP, or sham-vaccinated mice subsequently sensitized and challenged with allergen or PBS were cultured in triplicate in the presence of OVA (a-c) or RW (d-f) for 4 days and IL4 (a, d), IL13 (b, e), and TGF- $\beta$ (c, f) were quantified from supernatants as described in Methods. OVA and RW represent the sham-vaccinated and allergen sensitized groups. (g-i) CD4 ${ }^{+}$ T cells were isolated from IP-vaccinated and OVA sensitized/challenged (IP-OVA-T cells) or CP-vaccinated and OVA sensitized/challenged (CP-OVA-T cells) mice were cocultured, with T-depleted splenocytes from OVA-sensitized/challenged animals (OVA), in the presence of OVA. Similarly, (j-I) CD11c ${ }^{+}$DCs were isolated from IP (IP-OVA-DCs) or CP (CP-OVA-DCs) vaccinated animals as described in the Methods and cocultured, with OVA sensitized/challenged (OVA) DC-depleted splenocytes, in the presence of OVA. Supernatants were collected and IL4 (a, d, $\mathbf{g}$, j), IL13 (b, e, h, k), and TGF- $\beta(\mathbf{c}, \mathbf{f}, \mathbf{i}, \mathbf{I})$ levels were determined by ELISA. All cultures were performed in triplicate and experiments replicated at least three times. ${ }^{* *} P<0.01$ and ${ }^{* * *} P<0.001$. CP, control peptide; DC, dendritic cell; IL, interleukin; OVA, ovalbumin; PBS, phosphate-buffered saline; RW, ragweed; TGF- $\beta$, transforming growth factor-beta.

transferred into naïve age-matched recipients which were then allergen-sensitized and -challenged (Figure 3a) and allergic responses evaluated (Figures $3 \mathbf{b}-\mathbf{e}$ ). IP-T cell recipient mice (IP-T) post allergen challenge, compared with $\mathrm{CP}-\mathrm{T}$ cell-recipient (CP-T) or -allergic (OVA) mice, had minimal inflammatory cell influx in bronchoalveolar lavage (Figure 3b) and markedly reduced airway inflammation and mucous production (Figure $3 \mathrm{c}$ and Supplementary Figure S5) and low levels of OVA-specific IgE in serum (Figure 3e). Finally, IP-Trecipient mice showed airway responses to methacholine similar to those seen in allergen-naïve (PBS) mice (Figure 3d), whereas both $\mathrm{CP}-\mathrm{T}$ recipients and OVA groups had significant AHR. Splenocyte cultures from IP-T cell-recipient mice also produced significantly lower levels of IL4, IL10, IL13, and IFN- $\gamma$ following stimulation with OVA (Supplementary Figure S6a-d), whereas TGF- $\beta$ and IDO expression were again significantly elevated (Supplementary Figure S6e, f). Taken together, these data suggest that neonatal STAT6-IP vaccination promotes the formation of tolerant $\mathrm{CD} 4{ }^{+} \mathrm{T}$ cells which retain inhibitory activity when adoptively transferred. 
a

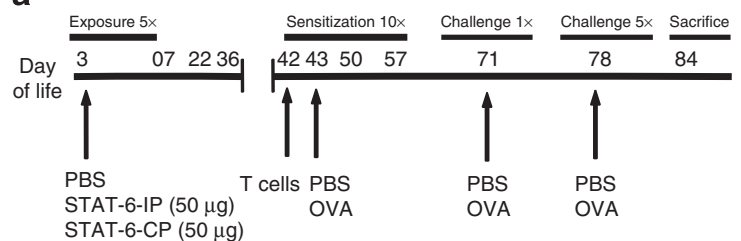

C

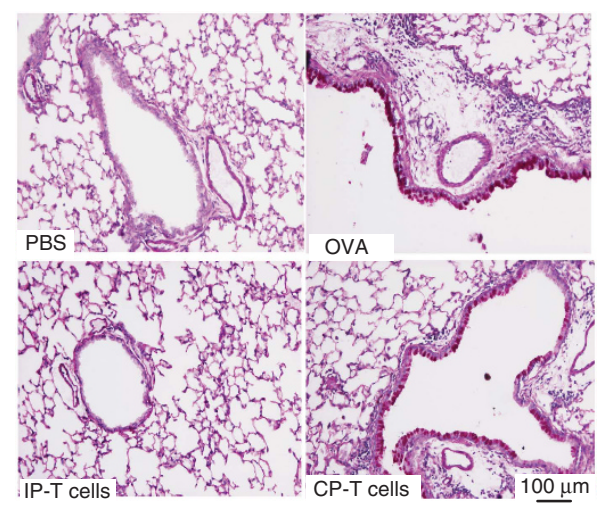

b

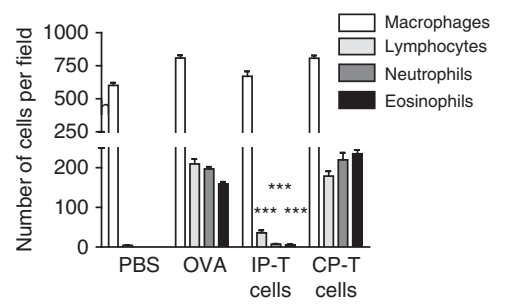

d
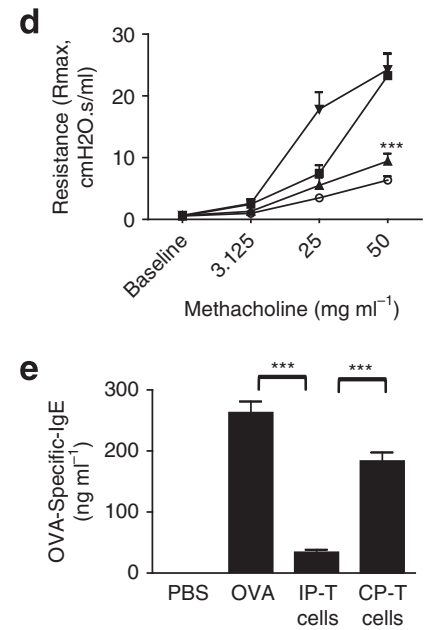

Figure 3 Adoptively transferred STAT6-IP CD4 ${ }^{+}$T cells prevent allergic airways disease in naïve recipient mice. (a) DO11.10 mice were vaccinated with STAT6-IP or STAT6-CP as described in Figure 1. CD4 ${ }^{+}$T cells were then isolated from STAT6-IP (IP-T cells) or STAT6-CP (CP-T cells) vaccinated mice and injected into the tail vein of naïve BALB/c mice. Twenty-four hours later, recipient mice were sensitized and challenged with

OVA per the protocol depicted in Figure 1a. (b) Differential cell counts from recipient mice were obtained from recovered BAL fluid and stained with Diff-Quick. White columns denote macrophages $(\square)$, lymphocytes ( $\square$ ) light grey, neutrophils ( $\square$ ) dark grey and eosinophils ( $\square$ ) black. (c) Lung sections were stained with Periodic Acid Schiff stain and mucus-positive cells were identified (original magnification $\times 100)$. (d) Bronchial airway hyperresponsiveness to methacholine following challenge with PBS or OVA was assessed in recipient mice using the Flexivent small animal ventilator. PBS (๑), OVA ( $\mathbf{\square})$, IP-Tcells $(\mathbf{\Delta})$, and CP-Tcells $(\boldsymbol{\nabla})$ respectively. (e) Serum OVA-specific-IgE from recipient animals. Six to eight animals per group per experiment and each experiment replicated at least twice. ${ }^{* \star} P<0.001$. BAL, bronchoalveolar lavage; $\mathrm{CP}$, control peptide; Ig, immunoglobulin; OVA, ovalbumin; PBS, phosphate-buffered saline.

\section{DCs from neonatal STAT6-IP vaccinated mice also mediate induction of allergen-specific tolerance in vivo}

Adoptive transfer experiments were also performed to assess the inhibitory potential of DCs harvested from STAT6-IPvaccinated mice. DCs were isolated, from the same donor animals used in the T-cell transfer experiments described above, and adoptively transferred into naïve animals that were then sensitized and challenged with allergen as shown in Figure 4a. Recipients of IP-DCs did not develop airway inflammation (Figures $\mathbf{4 b}$ and $\mathbf{c}$, and Supplementary Figure S5) or AHR (Figure 4d). OVA-specific IgE levels in these mice were similar to those from allergen-naive (PBS) mice (Figure 4e). In contrast, recipients of CP-DCs developed inflammation (Figure $4 \mathrm{~b}$ and c), AHR (Figure 4d), and OVAspecific IgE (Figure 4e) to levels that were similar to OVAallergic mice. Upon culture with OVA, splenocytes from recipients of IP-DCs produced less IL4, IL10, IL13, and IFN- $\gamma$, whereas TGF- $\beta$ levels were significantly elevated in this group (Supplementary Figure S7a-e). Finally, transcripts of IDO, often associated with tolerant DC phenotype, were also increased in these splenocytes cultures (Supplementary Figure S7f).

\section{STAT6-IP-mediated neonatal tolerance induction is TGF- $\beta$-dependent}

In all allergen-induced recall responses from STAT6-IPvaccinated mice, TGF- $\beta$ levels were significantly elevated relative to those from naïve (PBS), allergic (OVA, RW), or $\mathrm{CP}$-vaccinated mice. To determine whether TGF- $\beta$ was required for the observed STAT6-IP-mediated activity, vaccinated mice were treated with a pan-neutralizing anti-TGF- $\beta$ antibody or isotype control either before sensitization (Figure 5a) or challenge (Figure 5i). Anti-TGF- $\beta$ treatment negated the protective effects of neonatal STAT-6-IP vaccination when delivered at the time of OVA sensitization. Bronchoalveolar lavage fluid inflammatory cell influx (Figure 5b), airway inflammation and mucous production (Figure 5c, Supplementary Figure S8), AHR (Figure 5d), and OVA-specific IgE (Figure 5e) were all elevated in IP-vaccinated mice when TGF- $\beta$ was neutralized during OVA sensitization. Significantly, neutralizing TGF- $\beta$ in CP-vaccinated (Supplementary Fig S9) or sham-vaccinated OVA-sensitized mice (Figure 5) had no effect on OVA-induced airway inflammatory responses. In addition, cytokine levels from splenocyte cultures showed that neutralization of TGF- $\beta$ in IP-vaccinated mice 
at the time of OVA sensitization restored IL4, IL13, IL10, and IFN- $\gamma$ to those produced by splenocytes harvested from sham-vaccinated OVA mice (Supplemental Figure S10).
Moreover, compared with IP-vaccinated mice, there was a significant increase in the frequency (Figure 5f) and mean fluorescence intensity (Figure 5g) of IL4-expressing splenocyte a

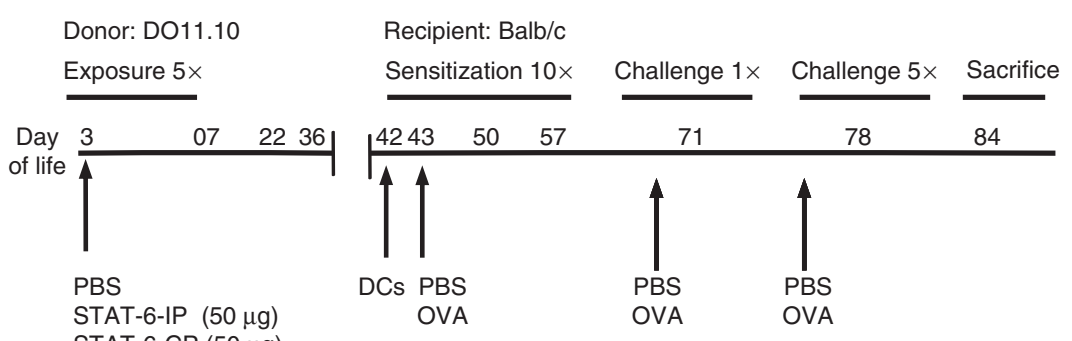

C

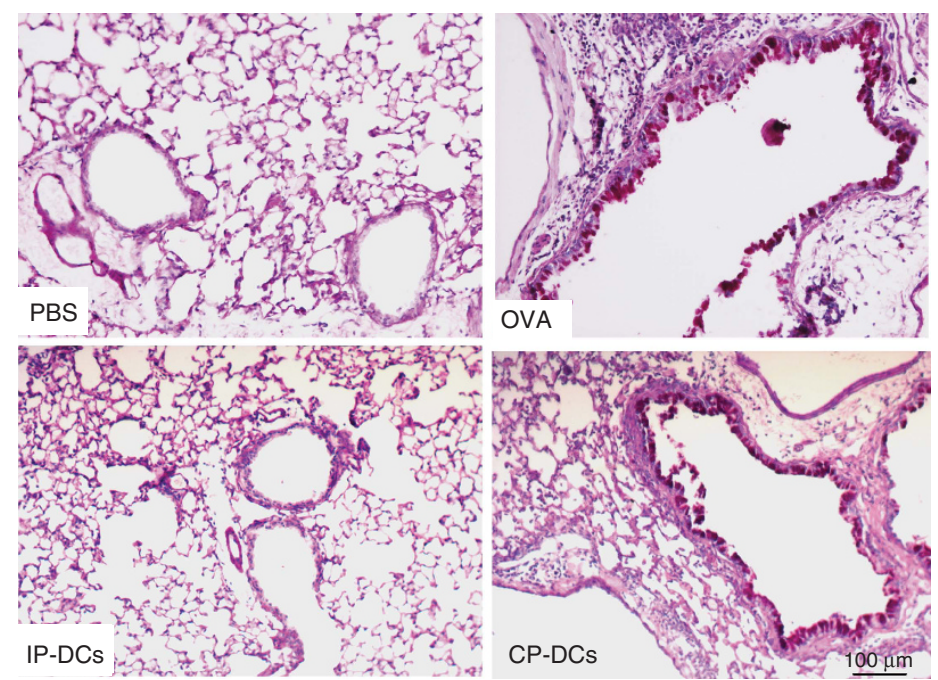

b

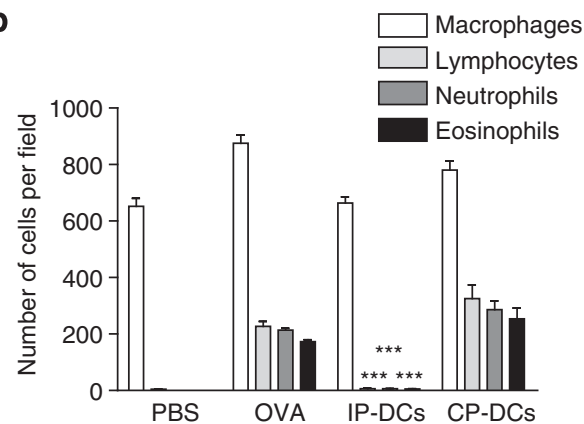

d

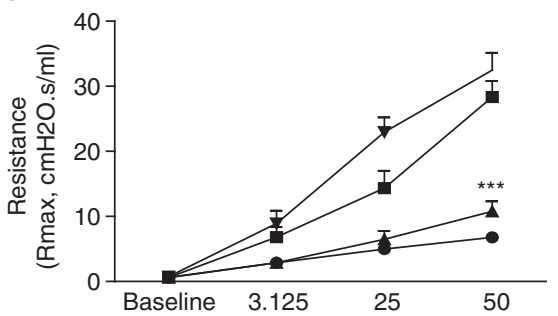

e

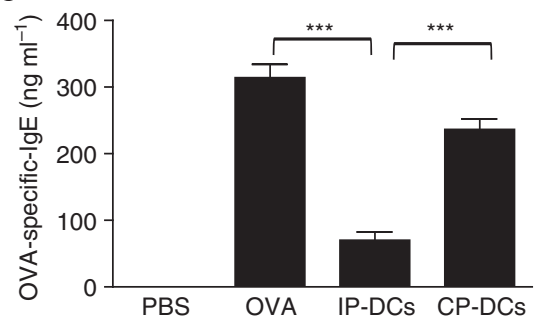

Figure 4 DCs from IP-vaccinated mice prevent allergic sensitization of naïve mice. (a) CD11c ${ }^{+}$DCs were isolated from STAT6-IP (IP) or STAT6-CP $(\mathrm{CP})$ vaccinated mice, as in Figures $4 \mathrm{a}$, and $5 \times 10^{5}$ cells were adoptively transferred intratracheally to naïve BALB/c mice. Recipient mice were sensitized and challenged with OVA and responses assessed. (b) Differential cell counts were obtained from recovered BAL fluid and stained with DiffQuick. White columns denote macrophages $(\square)$, lymphocytes $(\square)$ light grey, neutrophils $(\square)$ dark grey, and eosinophils ( $\square$ ) black. (c) Lung sections were stained with Periodic Acid Schiff stain and mucus-positive cells were identified (original magnification $\times 100$ ). (d) Bronchial airway hyperresponsiveness to methacholine following challenge with PBS or OVA was assessed using the Flexivent small animal ventilator. PBS (-), OVA ( $\boldsymbol{\square})$, IP-DC-recipients $(\boldsymbol{\Delta})$, and CP-DC-recipients $(\boldsymbol{\nabla})$, respectively. (d) Serum OVA-specific-IgE from recipient animals. Six to eight animals per group and experiments replicated at least twice. ${ }^{* \star \star} P<0.001$. BAL, bronchoalveolar lavage; $\mathrm{CP}$, control peptide; DC, dendritic cell; Ig, immunoglobulin; OVA, ovalbumin; PBS, phosphate-buffered saline.

Figure 5 Protective effects of STAT6-IP vaccination are TGF- $\beta$-dependent. (a) BALB/c mice were vaccinated with STAT6-IP or STAT6-CP. At the time of sensitization, in some animals, for each group, pan-anti-TGF- $\beta$ antibody ( $\alpha$ TGF- $\beta$ ) was given intranasally every other day during sensitization as depicted in a and allergic responses assessed post challenge. (b) Differential cell counts were obtained from recovered BAL fluid and stained with DiffQuick. White columns denote macrophages $(\square)$, lymphocytes ( $\square$ ) light grey, neutrophils ( $\square$ ) dark grey, and eosinophils ( $\square$ ) black. (c) Lung sections were stained with Periodic Acid Schiff stain and mucus-positive cells were identified (original magnification $\times 100)$. (d) Bronchial airway hyperresponsiveness to methacholine following challenge with PBS or OVA was assessed using the Flexivent small animal ventilator. PBS ( $)$ ), PBS + $\alpha$ TGF- $\beta(\bigcirc)$, OVA ( $\mathbf{\square})$, OVA $+\alpha$ TGF- $\beta(\square)$, IP $(\mathbf{\Delta})$, IP $+\alpha$ TGF- $\beta(\Delta)$. (e) Serum OVA-specific-IgE. (f) Intracellular cytokine staining gated on IL4 to compare the frequency of IL4 ${ }^{+} \mathrm{CD} 4^{+}$cells by flow cytometry as described in the methods. $\alpha \mathrm{TGF}-\beta$ treatment during sensitization restores formation of IL4 ${ }^{+} \mathrm{T}$ cells following allergen sensitization in IP-vaccinated mice. (g) Mean florescence intensity of IL4 ${ }^{+}$CD4 ${ }^{+} \mathrm{T}_{\text {cells from three independent }}$ experiments. (h) Isolated CD4 ${ }^{+}$T cells from whole-lung homogenates were stained for LAP and expression assessed by flow cytometry. (i) Anti-TGF- $\beta$ antibody, given only during allergen challenge, had no effect on airway responses. Mice, vaccinated with STAT6-IP or CP, were sensitized as depicted in i. At the time of challenge, these animals were treated with $\alpha$ TGF- $\beta$ antibody every other day. (j) Bronchial airway hyperresponsiveness to methacholine

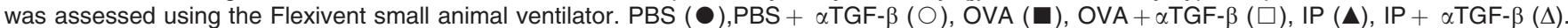
In contrast to Figures $6 c$, there were no significant differences in IP $(\boldsymbol{\Lambda})$ and IP $+\alpha$ TGF- $\beta(\Delta)$ when $\alpha$ TGF- $\beta$ was given only during challenge. For all experiments, $6-8$ animals per group and experiments were replicated at least twice. ${ }^{* * *} P<0.001$. BAL, bronchoalveolar lavage; CP, control peptide; Ig, immunoglobulin; IL, interleukin; LAP, latency-associated peptide; OVA, ovalbumin; PBS, phosphate-buffered saline; TGF- $\beta$, transforming growth factor-beta. 
T cells from mice treated with TGF- $\beta$-neutralizing antibody. Finally, the surface expression of LAP, associated with inducible Foxp $^{-}$regulatory $\mathrm{T}$ cells was reduced to baseline levels upon inhibition of TGF- $\beta$ (Figure 5h), suggesting that induction of $\mathrm{CD}^{+} \mathrm{LAP}^{+} \mathrm{T}$ cells was TGF- $\beta$-dependent in this model.

In contrast to the effects seen upon inhibition of TGF- $\beta$ at the time of OVA sensitization in IP-vaccinated mice, a

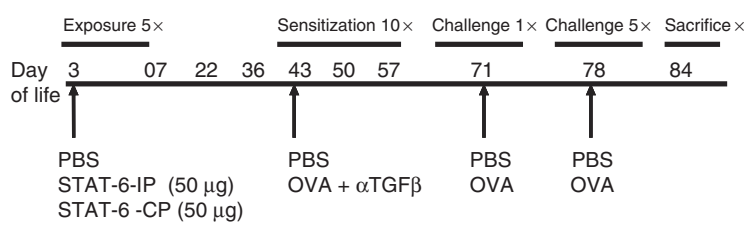

C

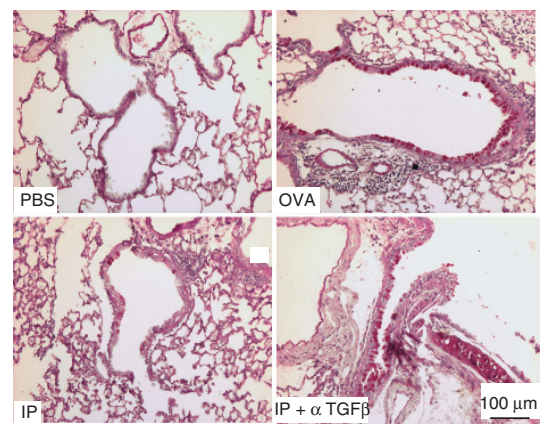

f

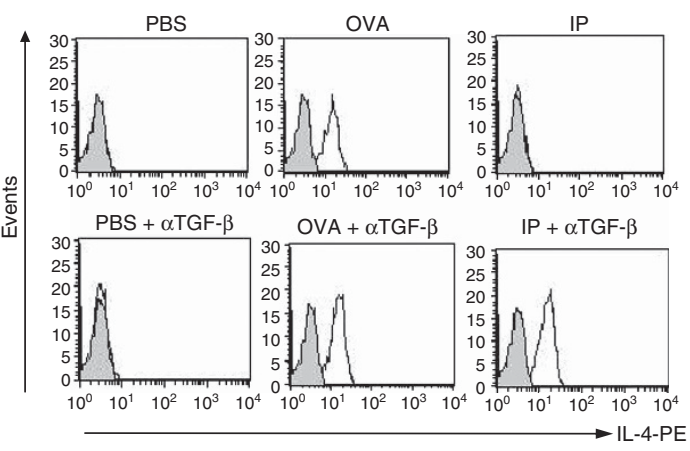

i

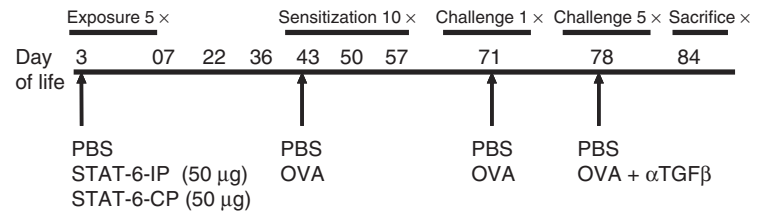

b

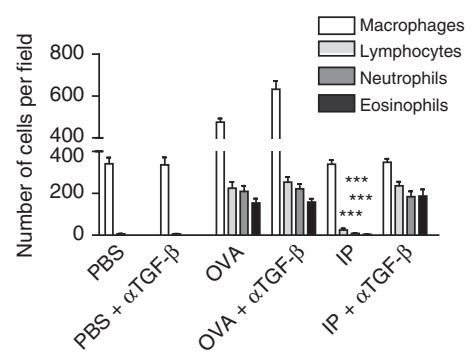

d

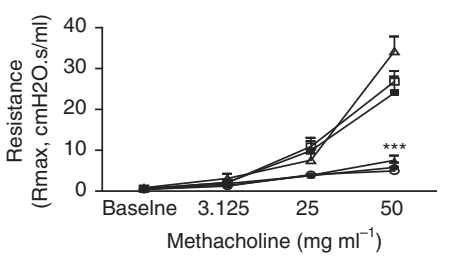

e

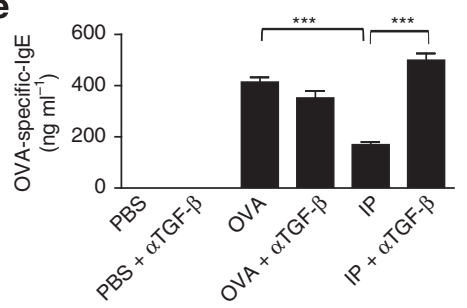

g

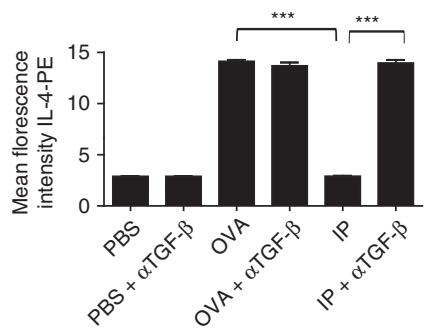

h

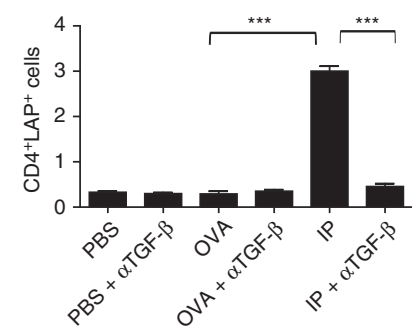

j

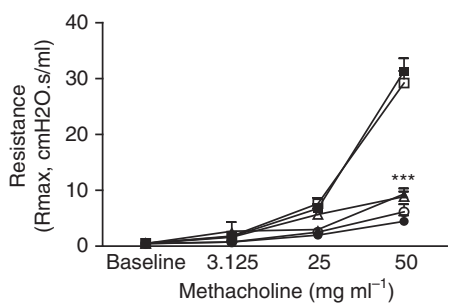


neutralization of TGF- $\beta$ at the time of OVA challenge (Figure 5i) had no effect on recall airway responses during challenge (Figure 5i) as exemplified by the lack of effect on AHR (Figure 5j).

Collectively, these data demonstrate that the outcome of allergen sensitization in mice previously vaccinated with STAT6-IP, is tolerance. Thus, although the activity of TGF- $\beta$ is critically important for the induction of tolerance, once established, the role of TGF- $\beta$ in perpetuating the phenotype appears to be minimal.

\section{Mechanisms of STAT6-IP vaccine-mediated tolerance induction}

STAT6-IP-vaccinated mice develop tolerance to allergen stimulation in the airways. TGF- $\beta$, implicated in induction of Treg cells, is a critically important element for tolerance induction in vaccinated mice as inhibition of TGF- $\beta$ activity prevents the protective effects of STAT6-IP vaccination (Figure 5). We have also demonstrated that DCs from STAT6-IP-vaccinated animals confer tolerance when adoptively transferred into unvaccinated mice (Figure 4). Tolerogenic DCs have been shown to modulate T-cell responses by inducing T-cell anergy, T-cell apoptosis, and induction of Tregs. ${ }^{29}$ Mechanisms include elaboration of Treg cytokines such as IL10 and TGF- $\beta$ and inhibition of T-cell activity through IDO expression. In STAT6-IP-vaccinated mice, IL10 was not elevated (Supplementary Figures S2c, S4a,c,S6b,S7b,S9d,S10b). We also assessed both TGF- $\beta$ and IDO expression in STAT6-IP-vaccinated mice. As shown in Figures $\mathbf{6} \mathbf{a}$ and $\mathbf{b}$, TGF- $\beta$ was significantly increased in splenocyte-derived CD11c ${ }^{+}$DCs from STAT6-IP-vaccinated mice. In addition to the increased TGF- $\beta$ levels, IDO mRNA was also increased in whole-lung homogenates (Figure 6c) and in splenocytes (Supplementary Figure S2e) from STAT6-IPvaccinated mice compared with controls. Increases in IDO are often associated with regulatory immune responses..$^{35,36}$ To assess the role of IDO in mediating tolerance induction, STAT6-IP DCs were cocultured for 3 days with OVA-sensitized splenocytes with and without the IDO inhibitor 1-Methyl-D-Tryptophan. After 3 days in culture, there were no differences observed in the proliferation of $\mathrm{T}$ cells between the groups, and IL13 levels were not different between 1-Methyl-D-Tryptophan-treated and -untreated STAT6-IP cultures (Figure 6d). However, there was a trend toward decreased TGF- $\beta$ from cocultures incubated with 1Methyl-D-Tryptophan (Figure 6e). Although not conclusive, these data suggest that increased IDO activity in DCs from STAT6-IP-vaccinated mice may play a role in the observed increase in TGF- $\beta$ expression leading to the induction of Treg cells in vaccinated mice.

To determine whether the $\mathrm{T}$ cells from vaccinated mice were indeed functional Treg cells, we compared T-cell phenotypes of both lung and splenocytes from vaccinated and control mice. There was a significantly increased population of $\mathrm{LAP}^{+}$ $\mathrm{T}$ cells in lungs of vaccinated mice (Figure $\mathbf{1 d}$ and $\mathbf{e}, 5 \mathbf{h}$ ), and the inhibition of TGF- $\beta$ during allergen sensitization reduced the frequency of $\mathrm{LAP}^{+} \mathrm{T}$ cells to control levels (Figure $5 \mathbf{h}$ ). The frequency of $\mathrm{CD} 4{ }^{+} \mathrm{CD} 25^{+}$Foxp $3^{+} \mathrm{T}$ cells was also increased in STAT6-IP-vaccinated mice compared with the other treatment groups (Figures $\mathbf{6 f}$ and $\mathbf{g}$ ). $\mathrm{T}$ cells from vaccinated and control animals were then incubated with carboxyfluorescein succinimidyl ester (CFSE)-stained $\mathrm{T}$ cells from sensitized mice and proliferation assayed by CFSE staining. As shown in Figures $\mathbf{6 h}$ and $\mathbf{i}$, there was a significant dosedependent suppression of $\mathrm{T}$-cell proliferation in the presence of STAT6-IP-derived CD4 $\mathrm{T}^{+}$cells compared with $\mathrm{T}$ cells from control mice.

\section{DISCUSSION}

In this study, we have shown that sustained modulation of mucosal immune responses can be achieved through STAT6-IP vaccination early in development. STAT6-IP vaccination resulted in tolerance to aeroallergens manifesting as minimal allergen-induced specific IgE and reduced or absent airways inflammation, TH2 cytokine elaboration, and AHR. These outcomes were similar to those of naïve non-allergen-exposed mice. On the other hand, mice that were sham-vaccinated or given STAT6-CP vaccine typically developed TH2-type AAD. Notably, IP vaccination also resulted in the polarization of $\mathrm{CD} 4{ }^{+} \mathrm{T}$ cells with increases in functional Treg cells and $\mathrm{CD}_{11 \mathrm{c}^{+}}$-tolerant DCs and when either these T cells or DCs were transferred to naïve hosts, the tolerant phenotype was recapitulated in the recipients. STAT6-IP-vaccinated mice also had increased TGF- $\beta$, and when TGF- $\beta$ activity was neutralized in IP-vaccinated mice, at the time of allergen sensitization, the protective effects of STAT6-IP vaccination on AAD were eliminated.

We have previously shown that the intranasal application of STAT6-IP in adult mice with AAD results in reduction in allergen-induced AHR and inflammation in allergic animals. ${ }^{24,25}$ STAT6-IP inhibitory effects on these allergic responses were observable for at least 2 weeks following a single treatment course despite the demonstrated limited halflife of STAT6-IP of $<12 \mathrm{~h}$ and despite repeated allergen challenges. ${ }^{25}$ In the present study, STAT6-IP vaccination of neonates affected immune responses 6 weeks later, suggesting the development of stable, phenotypically tolerant immunity to allergen stimulation. These findings support our hypothesis that, in the neonatal immune system, transient inhibition of STAT6 activity influences TH2 cell differentiation and function by changing the polarization of DCs before allergen-mediated activation occurs and thus raises the possibility of directed mucosal immunomodulation as a modality for primary prevention of airways allergic diseases.

The precise mechanism by which the STAT6-IP influences STAT-6 activity is currently under investigation. Preliminary work suggests that STAT6-IP does not consistently inhibit Tyr phosphorylation of STAT6 at any time point, nor does it inhibit STAT-6 activity early following IL4 stimulation. These data are similar to those presented by Patel and colleagues ${ }^{37}$ who identified a naturally occurring mutant form of STAT6 with a non-functional SH2 domain, STAT6c. This SH2 domain 


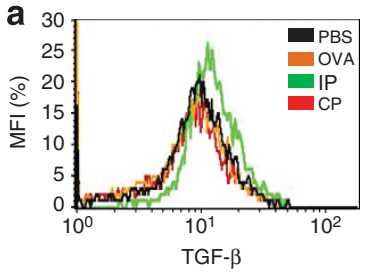

C
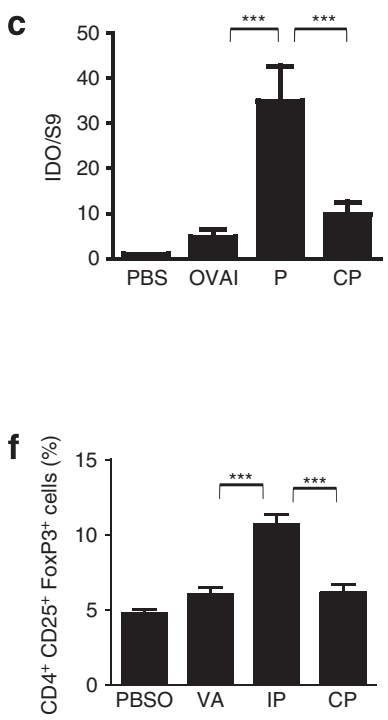

h

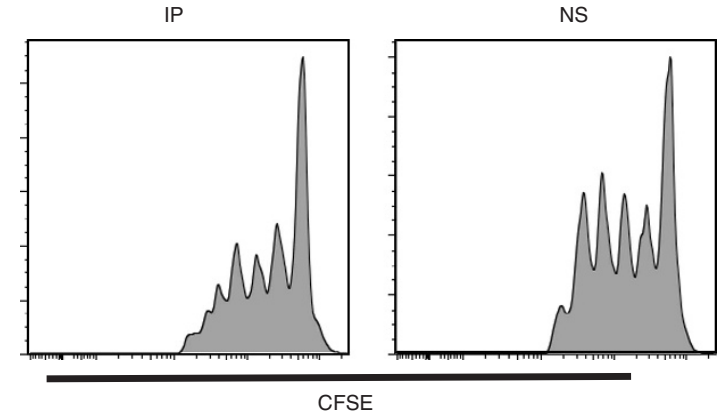

b

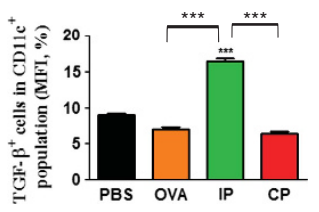

d
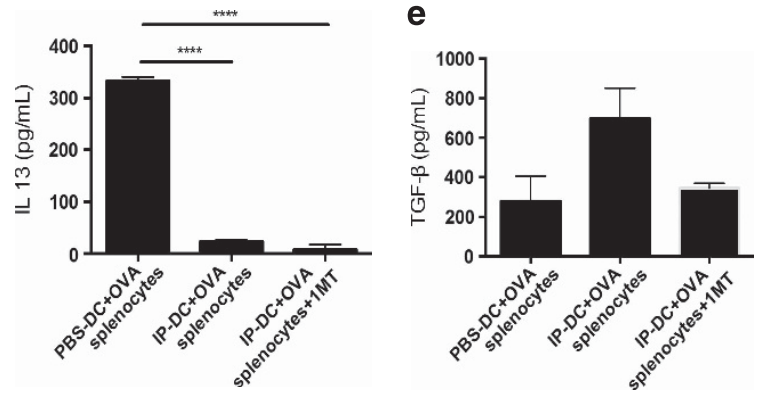

g

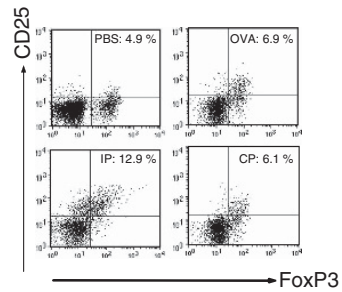

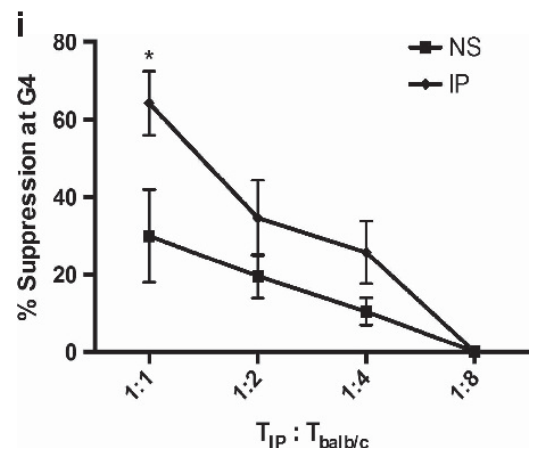

Figure 6 IP vaccination induces tolerogenic DCs and increased T regulatory cells able to suppress proliferation of sensitized T cells in vitro. $(\mathbf{a}, \mathbf{b})$ Intracellular cytokine staining of TGF- $\beta$ is increased in CD11c ${ }^{+}$cells from STAT6-IP-treated mice as assessed by flow cytometry. Representative mean fluorescence intensity (a) of the TGF-beta ${ }^{+} \mathrm{CD} 11^{+}$cells and mean MFI from three independent experiments is shown in $\mathbf{b}$. (c) IDO expression, as assessed by RT-PCR, was also increased in cells of IP-vaccinated mice isolated from lung (c). (d, e) Inhibition of IDO activity with 1-MT in cocultures. DC from IP-vaccinated or control animals were cocultured with OVA-sensitized DC-depleted splenocytes in the presence of OVA with and without the IDO inhibitor 1-MT. IL13 levels were reduced in STAT6-IP-DC containing cultures and this was unaffected by 1-MT, whereas there was a trend to decreased TGF- $\beta$ expression in the presence of 1-MT. $n=4$. (f, g) Frequency of CD4 ${ }^{+}, \mathrm{CD}_{2} 5^{+} \mathrm{FOXP}^{+}$cells were significantly increased in splenocytes from IP-vaccinated mice. $(\mathrm{h}, \mathrm{i}) \mathrm{CD} 4^{+} \mathrm{T}$ cells from IP-vaccinated mice significantly suppressed proliferation of sensitized T cells $(\mathbf{h})$ in a dose-dependent manner (i), measured by flow cytometry. ${ }^{\star} P<0.05,{ }^{\star \star} P<0.01,{ }^{\star \star \star} P<0.001 .1$-MT, 1 -Methyl-D-Tryptophan; DC, dendritic cell; IDO, indolamine 2,3-dioxygenase; IL, interleukin; OVA, ovalbumin; TGF- $\beta$, transforming growth factor-beta.

mediates dimerization and consequently nuclear translocation of STAT6. Their data indicate that the mutant STAT6c protein only modestly inhibited Tyr phosphorylation of the wild-type STAT6 and yet was a potent inhibitor of STAT6 activity, most likely through the inhibition of STAT6 dimerization. STAT6IP, upon binding to the SH2 domain of an activated STAT6 monomer may function similarly, by blocking DNA binding of the full-length wild-type STAT6 protein.

We have previously shown that reductions in the levels of STAT6-dependent cytokines/chemokines, such as IL13, IL5, and CCL11 (eotaxin), occurs following mucosal STAT6-IP treatment in established allergic disease. ${ }^{24,25}$ In this study, in addition to changes in $\mathrm{TH} 2$ cytokine expression, neonatal vaccination-induced airway immune responses to allergen were characterized by increased expression of IDO and TGF- $\beta$. IDO is involved in tryptophan metabolism that catalyzes the initial rate-limiting step of tryptophan degradation along the kynurenine pathway. ${ }^{38}$ Tryptophan starvation by IDO consumption inhibits T-cell activation whereas products of tryptophan catabolism, such as kynurenine derivatives and 
$\mathrm{O}_{2}$-free radicals, regulate T-cell proliferation and survival. ${ }^{35,38}$ IDO can also bias naïve $\mathrm{CD} 4^{+} \mathrm{T}$ cells to differentiate into Foxp3 ${ }^{+}$Tregs in vitro. ${ }^{36,39}$ In addition, IDO-expressing DCs have been shown to inhibit T-cell proliferation. ${ }^{40}$ In the present work, the inhibition of IDO in OVA-sensitized splenocytes cocultured with STAT6-IP DCs had no effect on proliferation after 3 days (data not shown), but there was a trend to reduction of TGF- $\beta$ (Figure 6e). In addition, there was persistent reduction of IL13 expression in these cocultures even in the presence of the IDO inhibitor 1-Methyl-D-Tryptophan (Figure 6d). Altogether these data suggest that the induction of IDO expression following neonatal STAT6-IP vaccination may elaborate the tolerant phenotype by preferentially increasing TGF- $\beta$ production leading to the observed induction of Treg cells (Figures 1d,5h,6a-i), whereas subsequent STAT6-IP DC interactions with sensitized T cells inhibit elaboration of IL13 through an IDO-independent mechanism..

Developmental programming of immune responses appears to be most efficient early in life. Abundant evidence suggests that late fetal and early postnatal immune responses are fundamentally different from those of adults and that interventions during the critical window of vulnerability can lead to programming of DCs and T-cell responses with long-term mucosal and systemic effects. ${ }^{27-29,41}$ In the airways, postnatal stimuli lead to the migration of immature bone marrow DCs to the airways. ${ }^{12}$ Polarization of these DCs is influenced by the local environment and the type of stimuli available. ${ }^{10-12,42}$ Establishment of a regulatory-type environment, in balance with activation, is a key to prevention of allergy in the long term. ${ }^{8,10}$

Studies have demonstrated that tolerance to food and inhalant antigens can be induced early in life using breast milk components and bacteria-derived antigens. ${ }^{1,43-45}$ We have previously demonstrated that when neonatal mice are exposed intranasally to lipopolysaccharide, there are sustained increases in $\mathrm{CD} 25^{+}, \mathrm{Foxp}^{+} \mathrm{T}$ cells that, when transferred into naïve recipients, confer protection from $\mathrm{AAD} .{ }^{30}$ Breast milk contains factors including TGF- $\beta$ and immune complexes in addition to environmental antigens that collectively have been shown to confer allergen-specific resistance to allergic diseases in animal models. ${ }^{43,44}$ Interestingly, TGF- $\beta$ levels in breast milk inversely correlates with the development of allergies in humans ${ }^{46,47}$ and recently, mutations in TGF- $\beta$, TGFBR11, and TGFBR2 have been demonstrated in patients strongly predisposed to develop allergic disease also implicating the absence or reduced activity of TGF- $\beta$ in the development of allergies. ${ }^{48}$ In the present study, we have shown that active tolerance induction to aeroallergens can be achieved by neonatal airways vaccination with STAT6-IP associated with increased allergen-induced TGF- $\beta$ production.

Numerous studies have shown that TGF- $\beta$ suppresses the activity, proliferation, and/or survival of various inflammatory cells including TH2 cells, B cells, macrophages, and eosinophils. $^{34,49-52}$ Our data demonstrate that the induction of aeroallergen tolerance by the STAT6-IP was TGF- $\beta$-dependent and was coupled with changes in the Foxp $3^{+}$T-cell population
(Figure $6 \mathbf{f}$ and $\mathbf{g}$ ). Transfer of the tolerant phenotype was achieved by $\mathrm{CD} 4{ }^{+}$T-cell adoptive transfer into naïve recipients and in in vitro coculture experiments and T cells from STAT6-IP-vaccinated mice actively suppressed the proliferation of T cells from allergen-sensitized mice (Figure $\mathbf{6 h}$ and i).These $\mathrm{T}$-cell data suggest that the $\mathrm{T}$ cells generated following STAT6-IP vaccination were functional Tregs. In these complex in vivo experimental systems, it is possible that other cell types, not studied herein, including airway macrophages and structural cells contributed to the development of tolerance. However, the additional data showing the effectiveness of DC cell transfer as a means to prevent allergic sensitization suggest that STAT6-IP vaccination also resulted in the stable polarization of DCs, which promoted functional allergen tolerance (Figure 4) in a TGF- $\beta$-dependent manner (Figure 5).

In summary, these data demonstrate, for the first time, a novel strategy for experimental AAD prevention through targeted immuno-polarization and show that this single intervention, early in development, supports the formation of regulatory pathways resulting in immune homeostasis, thus preventing allergic asthma.

\section{METHODS}

Peptide synthesis. STAT-6-inhibitory peptides (STAT6-IP or IP) and STAT6-control peptides (STAT6-CP or CP) were synthesized by the University of Calgary Integrated Peptide Services (Calgary Alberta, Canada). Peptides are comprised of a derivative of the TAT protein transduction domain, YARAAARQARA. ${ }^{53}$ This sequence is coupled to an eight amino acid sequence surrounding tyrosine 641 in murine STAT- 6 . In the STAT-6-IP, the tyrosine residue is phosphorylated (GRG*YVSTT) and in the control STAT-6-CP peptide, this residue is replaced by a phenylalanine (GRGFVSTT). Peptides were amidated at the carboxyl terminus and purified by reverse phase high-performance liquid chromatography and analyzed by mass spectrometry. Peptide sequences, uptake, stability in vivo, and inhibitory effects of the STAT-6-IP have been detailed previously in an acute OVA-induced ${ }^{24}$ and in chronic RW-induced models of AAD. ${ }^{25}$

Animals. Six to 8 -week-old BALB/c mice and BALB/c breeding pairs were obtained from Harlan-Spraque Dawley (Indianapolis, IN). OVA T-cell receptor transgenic DO11.10 mice, used to supply donor cells for adoptive transfer experiments, were obtained from Jackson Laboratories (Bar Harbor, ME). Mice were bred and housed in a conventional animal facility at the Meakins-Christie Laboratories. For each experimental condition, a minimum of six to eight animals were used. All studies followed Canadian Council of Animal Care (CCAC) guidelines and were approved by the Animal Care Committee of McGill University.

Peptide vaccination. Beginning on the third day of life, $50 \mu \mathrm{g}$ of either STAT6-IP or STAT6-CP, or PBS, was administered intranasally in a volume of $10 \mu \mathrm{l}$ daily for 5 days (Figure 1a).

Allergen sensitization and challenge. For acute OVA-induced AAD: At the age of 6-8 weeks, awake mice were sensitized 5 days per week for 2 weeks by local instillation of $10 \mu$, in each nare, of $1 \%$ OVA (SigmaAldrich, St Louis, MO) in PBS as previously described. ${ }^{24,33}$ Following 1 week of rest, the mice were similarly challenged once with OVA, and 1 week later, animals were briefly anesthetized with isoflurane and OVA challenged for five consecutive days and assayed $24 \mathrm{~h}$ after the final challenge (Figure 1a). 
For chronic RW-induced AAD: Awake animals were sensitized 5 days per week for 5 weeks by local instillation of $10 \mu \mathrm{l}$ in each nare of $1 \%\left(10 \mathrm{mg} \mathrm{ml}^{-1}\right.$ ) RW (Giant Ragweed, extracted from Ambrosia trifida, Sigma-Aldrich) in PBS as previously described. ${ }^{25}$ After a 2 week rest, mice were challenged with $1 \%\left(10 \mathrm{mg} \mathrm{ml}^{-1}\right.$, dry weight) Amba I (Short Ragweed, extracted from Ambrosia artemisiifolia pollen grains, Greer, Lenoir, NC) in PBS once per day for five consecutive days and assayed $24 \mathrm{~h}$ following the final challenge (Figure 1f). In some experiments, mice were briefly anaesthetized with isoflurane prior to Amba I challenges.

Assessment of AHR by methacholine challenge. Total respiratory resistance was measured $24 \mathrm{~h}$ after OVA or RW challenge using a small animal ventilator (FlexiVent, SCIREQ, Montreal, QC, Canada) as described in detail elsewhere. ${ }^{25}$ Briefly, mice were deeply anesthetized with xylazine hydrochloride (NovaPharm, Toronto, ON, Canada) followed by sodium pentobarbital (Sandoz, Montreal, QC, Canada; CEVA, Santé Animale, France) and paralyzed with pancuronium bromide. Heart rate was monitored by electrocardiogram to ensure adequate anesthesia throughout the procedure. Mice were ventilated quasi-sinusoidally with a tidal volume of $8 \mathrm{ml} \mathrm{kg}^{-1}$ and respiratory rate of 150 breaths/min. Methacholine was given by nebulizer (Aeroneb, SCIREQ, Montreal, QC, Canada) at doses of 3.125, 25, and $50 \mathrm{mg} \mathrm{ml}^{-1}$ and maximal resistance was obtained for each graded dose of methacholine.

Measurement of allergen-specific-IgE in sera. Blood was obtained from animals post challenge by postmortem intracardiac puncture. OVA- and ragweed-specific IgE was assayed as described previously. ${ }^{24,25,30}$ Specific IgE was quantified by ELISA (Pharmingen OptEIA IgE Kit, San Diego, CA) with the following modifications: serum was incubated overnight at $4{ }^{\circ} \mathrm{C}$ with protein $\mathrm{G}$ sepharose beads (Amersham Bioscience, Piscataway, NJ) prior to loading onto ELISA plates that had been previously coated with OVA or short RW. Standards were plated as per the OptEIA protocol. Samples were incubated overnight at $4^{\circ} \mathrm{C}$ and ELISA performed as per protocol. The specific antibodies were quantified with mouse IgE ELISA sets (BD Biosciences Pharmingen, San Diego, CA).

Differential cell counts in bronchoalveolar lavage fluid. Immediately postmortem, lungs were lavaged twice in situ with $0.75 \mathrm{ml}$ of icecold saline. The returned fractions were pooled and centrifuged. The pellets were used for total and differential cell counts as previously described. ${ }^{33}$ Briefly, red blood cells were lysed using ACK lysing buffer (PharM Lyse, BD Biosciences, Mississauga, ON, Canada). Cells were spun onto glass slides and stained using the Diffquick method (Dade Behring, Deerfield, IL). Differential cell counts were obtained manually under light microscopy. High power $(\times 2-3)$ fields were counted per slide and means obtained.

Histological analysis of lung tissues. Histology was performed, as described previously. ${ }^{36}$ Briefly, lungs were slowly inflated with $1 \mathrm{ml}$ formalin, isolated, and then placed entirely in formalin. The specimens were embedded in paraffin, and $0.5-\mu \mathrm{m}$ sections were cut. To assess inflammation, slides were stained with Hematoxylin \& Eosin, and to assess mucus production, slides were stained with Periodic Acid Schiff.

Splenocyte culture and cytokine assessment. Single-cell suspensions were prepared from whole spleen as described previously. ${ }^{25}$ Briefly, erythrocytes were lysed by ACK lysing buffer, and the washed splenocytes were resuspended at $5 \times 10^{6}$ cells $/ \mathrm{ml}$ in complete RPMI1640 medium with $10 \%$ heat-inactivated fetal bovine serum, $2 \mathrm{~mm}$ L-glutamine, $50 \mu \mathrm{M} 2-\mathrm{ME}, 100 \mathrm{U} \mathrm{ml}^{-1}$ penicillin, and $100 \mu \mathrm{g} \mathrm{ml}^{-1}$ streptomycin sulfate. Splenocytes were then cultured for 4 days at $37^{\circ} \mathrm{C}$ with $5 \% \mathrm{CO}_{2}$ in the presence of OVA or Amba I $\left(10 \mathrm{mg} \mathrm{ml}^{-1}\right)$. Supernatants were stored at $-80{ }^{\circ} \mathrm{C}$ prior to quantifying cytokine levels by ELISA (see below).

Murine IL4, IL5, IL10, IL13, TGF- $\beta$, and IFN- $\gamma$ levels in supernatants of the allergen-stimulated cultured splenocytes were quantified using ELISA kits purchased from eBioscience (San Diego, CA) according to the manufacturer's instructions.

$\mathrm{CD}^{+}{ }^{+}$-cell and CD11c ${ }^{+} \mathrm{DC}$ isolation for coculture. For coculture experiments, spleen cells were prepared from naïve or previously sensitized mice. $\mathrm{CD} 44^{+} \mathrm{T}$ cells or $\mathrm{CD} 11 \mathrm{c}^{+}$DCs were depleted by MACS using anti-CD4 or anti-CD11c coupled beads and LS separation column (Miltenyi Biotech, San Diego, CA). CD4 ${ }^{+} \mathrm{T}$ depleted or DC-depleted splenocytes had $<0.3 \%$ detectable cells of the depleted phenotype (CD4 of CD11c, respectively) following depletion as assessed by flow cytometry. Depleted splenocytes $\left(5 \times 10^{6}\right.$ cells $\left./ \mathrm{ml}\right)$ were cocultured with T cells $\left(5 \times 10^{6}\right)$ or DCs $\left(5 \times 10^{5}\right)$ from previously MACS-purified IP or CP vaccinated, OVA-sensitized/challenged mice, or PBS-only animals. Purity of isolated cells, as assessed by flow cytometry, was $>97 \%$ for $\mathrm{CD}^{+}{ }^{+} \mathrm{T}$ cells and $>98 \%$ for $\mathrm{CD} 11 \mathrm{c}^{+}$DCs. In the $\mathrm{CD} 11 \mathrm{c}^{+}$population, the frequency of CD $11 \mathrm{~b}^{+}$ cells was also analyzed by flow cytometry; $<3 \%$ of the $\mathrm{CD} 11 \mathrm{c}^{+}$cells were $\mathrm{CD} 11 \mathrm{~b}^{+}$. After 4 days coculture with OVA, cells were harvested and analyzed by flow cytometry. Culture supernatants were then collected for cytokine analysis by ELISA. Cocultures using cells isolated from IP- or CP-vaccinated, non-allergen-sensitized mice are shown in Supplementary Figure S4. In some DC coculture experiments, $200 \mu \mathrm{M}$ of 1-methyltryptophan was also added to the culture media to determine the effect of IDO inhibition on cell proliferation and cytokine production after 3 days in culture.

T-cell suppression assay. CD ${ }^{+} \mathrm{T}$ cells were purified from spleens of OVA-sensitized mice and incubated with CFSE $(5 \mu \mathrm{M})$ for $8 \mathrm{~min}$ at room temperature. Cells were then washed and resuspended in complete medium for $15 \mathrm{~min}$. CFSE-labeled CD $4^{+} \mathrm{T}$ cells (responder $\mathrm{T}$ cells) were mixed with $\mathrm{CD} 4{ }^{+} \mathrm{T}$ cells, isolated as described above, from STAT6-IP-treated or sham control mice in ratios of 1:1 to 1:8, and cocultured in 24-well plates. Cells were stimulated with $10 \mathrm{mg} \mathrm{ml}^{-1}$ OVA, in the presence of $2 \times 10^{5}$ purified CD $11 c^{+}$DCs from allergennaïve mice. After 3 days, cells were harvested, and CFSE dilution was analyzed by means of flow cytometry. The percentage of suppression was calculated as: $\%$ suppression $=\left(\mathrm{P}_{\mathrm{G} 4}-\mathrm{P}_{\mathrm{G} 4(1: 8)}\right) / \mathrm{P}_{\mathrm{G} 4(1: 8)}\left(\mathrm{P}_{\mathrm{G} 4}\right.$ : percentage of $\mathrm{G} 4$ cells (cells at generation 4 ) among responder $\mathrm{T}$ cells).

Adoptive transfer of $\mathrm{CD}^{+} \mathbf{T}$ cells or $\mathrm{CD} 11 \mathrm{c}^{+} \mathbf{D C}$. For adoptive transfer experiments, $5 \times 10^{6}$ MACS-purified $\mathrm{CD}^{+} \mathrm{T}$ cells as described above, from IP- or CP-vaccinated or PBS sham-vaccinated DO11.10 mice, were injected into tail vein of naïve $B A L B / c$ recipients in a volume of $50 \mu \mathrm{l}$ of normal saline. Twenty-four hours later, recipient mice were sensitized and challenged with OVA as depicted in Figure 4a. In other experiments, $5 \times 10^{5}$ purified $\mathrm{CD} 11 \mathrm{c}^{+} \mathrm{DCs}$ from these same donor mice were injected intratracheally into naïve BALB/c recipients in a volume of $50 \mu \mathrm{l}$ of normal saline. Twenty-four hours later, these mice were sensitized and challenged with allergen as depicted in Figure 5a.

In vivo treatment with anti-TGF- $\beta$ antibody. Monoclonal pan-antiTGF- $\beta 1,-\beta 2,-\beta 3$ (MAB 1835) and normal mouse IgG1 isotype control (MAB002 were purchased from R\&D System (Minneapolis, MN). Animals were treated with $50 \mu \mathrm{g}$ anti-TGF- $\beta$ pan-neutralizing antibody or isotype control intransally every second day during sensitization or challenge with allergen (Figures $\mathbf{6 a}$ and $\mathbf{i}$ ).

RNA extraction and real-time RT-PCR. To assess mRNA levels of inflammatory genes in lung tissues, the total cellular RNA was extracted from the lungs using RNeasy Mini Kit, according to the manufacturer's protocol (Qiagen, Toronto, ON, Canada), and reversetranscribed using SuperScript II reverse transcriptase (Invitrogen Life Technologies, Carlsbad, CA). Real-time quantitative PCR was performed with a LightCycler System (Roche Applied Sciences, Indianapolis, IN) using QuantiTect SYBR Green (Qiagen). Each target was quantified using four 10 -fold serial dilutions of standards prepared from PCR amplicons that had been gel-purified and quantified using a Fluorochem 8000 imaging system and AlphaEase software (Alpha 
Innotech, San Jose, CA). Values were then normalized to GAPDH that had been reverse-transcribed, PCR-amplified, and quantified. The following mouse primers were used: Muc2, sense $5^{\prime}$-GCTGAC GAGTGGTTGGTGAAT G-3' and antisense $5^{\prime}$-GATGAGGTGGCA GACAGGAGAC-3' ${ }^{\prime}$, Muc5ac, sense 5'-CAGCCGAGAGGAGGGTTT GATCT- $3^{\prime}$ and antisense $5^{\prime}$-AGTCTCTCTCCGCTCCTCTCAAT- $3^{\prime}$. Eotaxin-1 (CCL11), sense $5^{\prime}$-GGGCAGTAACTTCCATCTGTCTCC- $3^{\prime}$ and antisense $5^{\prime}$-CACTTCTTCTTGGGGTCAGC- $3^{\prime}$. GAPDH, sense $5^{\prime}$-GCCATGGACTGTGGTCATGA- $3^{\prime}$ and antisense $5^{\prime}$-TTCACCAC CATGGAGAAGGC-3'. IDO, sense $5^{\prime}$-GTACATCACCATGGCGT ATG-3' and antisense 5'-CGAGGAAGAAGCCCTTGTC-3'.

Flow cytometric analysis. Surface markers, intracellular cytokines, and FoxP3 were evaluated by flow cytometry. Splenocytes cultured for 4 days with Amba I or OVA were stimulated for $5 \mathrm{~h}$ with murine antiCD3 $\left(0.5 \mu \mathrm{g} \mathrm{ml}^{-1}\right.$; clone 2C11, BD Pharmingen, Mississauga, ON, Canada) and monensin (GolgiStop; BD Biosciences), according to the manufacturer's instructions. Cells were then washed, permeabilized with saponin (Perm/Wash; BD Biosciences), and fixed in formaldehyde and PBS (Cytofix/Cytoperm; BD Biosciences) for $30 \mathrm{~min}$. Cell surface markers were stained with labeled rat anti-mouse CD4, CD25, LAP, CD11c, or intracellular proteins IL4, IFN- $\gamma$, IL10, TGF- $\beta$, or Foxp3 on ice for $30 \mathrm{~min}$ and then washed with PBS and analyzed on a FACSCalibur (BD). Ten thousand cells were counted from each sample and data were analyzed with BD flow cytometer and CellQuest Software. Cells were also stained with respective isotype control antibodies.

Statistical analysis. The results represented \pm s.e.ms of six to eight replicates/experiment and each experiment was repeated at least three times. The data were analyzed using one-way analysis of variance, followed by Tukey's post hoc tests for individual group comparisons. A value of $P<0.05$ was considered significant.

SUPPLEMENTARY MATERIAL is linked to the online version of the paper at http://www.nature.com/mi

\section{ACKNOWLEDGMENTS}

This work was funded by the Canadian Institutes of Health Research (CIHR grant 89725 CTM), the McGill University Health Center Research Institute (MUHCRI), the Montreal Chest Institute and the Strauss Family Foundation, JT Costello Memorial Research Fund, the Fonds de Recherche en Sante du Quebec (FRSQ), and the Montreal Children's Hospital Research Institute.

\section{DISCLOSURE}

The authors declare no conflict of interest.

c) 2015 Society for Mucosal Immunology

\section{REFERENCES}

1. Ege, M.J. et al. Exposure to environmental microorganisms and childhood asthma. N. Engl. J. Med. 364, 701-709 (2011).

2. Alfven, T. et al. Allergic diseases and atopic sensitization in children related to farming and anthroposophic lifestyle-the PARSIFAL study. Allergy 61 414-421 (2006).

3. Holt, P.G. et al. Toward improved prediction of risk for atopy and asthma among preschoolers: a prospective cohort study. J. Allergy Clin. Immunol. 125, 653-659 (2010).

4. Carlsten, C. et al. Indoor allergen exposure, sensitization, and development of asthma in a high-risk birth cohort. Pediatr. Allergy Immunol. 21, e740e746 (2010)

5. Toelle, B.G. et al. Outcomes of the Childhood Asthma Prevention Study at 11.5 years. J Allergy Clin. Immunol. 132, 1220-1222 (2013).

6. West, C.E., Hammarstrom, M.L. \& Hernell, O. Probiotics in primary prevention of allergic disease - follow-up at 8-9 years of age. Allergy 68, 1015-1020 (2013)
7. Maas, T. et al. Mono and multifaceted inhalant and/or food allergen reduction interventions for preventing asthma in children at high risk of developing asthma. Cochrane Database Syst Rev., CD006480 (2009).

8. Holt, P.G. \& Sly, P.D. Viral infections and atopy in asthma pathogenesis: new rationales for asthma prevention and treatment. Nat. Med. 18, 726-735 (2012).

9. Kraft, M. Asthma phenotypes and interleukin-13 - moving closer to personalized medicine. N. Engl. J. Med. 365, 1141-1144 (2011).

10. Awasthi, S., Singh, B., Welliver, R.C. \& Dietert, R.R. Lung dendritic cell developmental programming, environmental stimuli, and asthma in early periods of life. J. Allergy (Cairo) 2012, 176468 (2012).

11. Strickland, D.H. et al. Defective aeroallergen surveillance by airway mucosal dendritic cells as a determinant of risk for persistent airways hyper-responsiveness in experimental asthma. Mucosal Immunol 5, 332-341 (2012).

12. Holgate, S.T. Innate and adaptive immune responses in asthma. Nat. Med. 18, 673-683 (2012).

13. Perkins, C. et al. Selective stimulation of IL-4 receptor on smooth muscle induces airway hyperresponsiveness in mice. J. Exp. Med. 208, 853-867 (2011).

14. Kuperman, D.A. et al. Direct effects of interleukin-13 on epithelial cells cause airway hyperreactivity and mucus overproduction in asthma. Nat. Med. 8, 885-889 (2002).

15. Kaiko, G.E., Horvat, J.C., Beagley, K.W. \& Hansbro, P.M. Immunological decision-making: how does the immune system decide to mount a helper T-cell response? Immunology 123, 326-338 (2008).

16. Hammad, H. \& Lambrecht, B.N. Dendritic cells and epithelial cells: linking innate and adaptive immunity in asthma. Nat. Rev. Immunol. 8, 193-204 (2008).

17. Kelly-Welch, A.E., Hanson, E.M., Boothby, M.R. \& Keegan, A.D. Interleukin-4 and interleukin-13 signaling connections maps. Science 300, 1527-1528 (2003).

18. Quelle, F.W. et al. Cloning of murine Stat6 and human Stat6, Stat proteins that are tyrosine phosphorylated in responses to IL-4 and IL-3 but are not required for mitogenesis. Mol. Cell Biol. 15, 3336-3343 (1995).

19. Zheng, W. \& Flavell, R.A. The transcription factor GATA-3 is necessary and sufficient for Th2 cytokine gene expression in CD4 Tcells. Cell 89, 587-596 (1997).

20. Kuperman, D.A. \& Schleimer, R.P. Interleukin-4, interleukin-13, signal transducer and activator of transcription factor 6 , and allergic asthma. Curr. Mol. Med. 8, 384-392 (2008).

21. Cao, Y. et al. The effects of antisense interleukin- 4 gene transferred by recombinant adeno-associated virus vector on the airway remodeling in allergic rats. J. Asthma. 47, 951-958 (2010).

22. Oh, C.K., Geba, G.P. \& Molfino, N. Investigational therapeutics targeting the IL-4/IL-13/STAT-6 pathway for the treatment of asthma. Eur. Respir. Rev. 19, 46-54 (2010)

23. Ma, Y. et al. Sustained suppression of IL-13 by a vaccine attenuates airway inflammation and remodeling in mice. Am. J. Respir. Cell Mol. Biol. 48, 540-549 (2013).

24. McCusker, C.T. et al. Inhibition of experimental allergic airways disease by local application of a cell-penetrating dominant-negative STAT-6 peptide. J. Immunol. 179, 2556-2564 (2007).

25. Wang, Y., Li, Y., Shan, J., Fixman, E. \& McCusker, C. Effective treatment of experimental ragweed-induced asthma with STAT-6-IP, a topically delivered cell-penetrating peptide. Clin. Exp. Allergy. 41, 1622-1630 (2011).

26. Gasparoni, A. et al. Age-related changes in intracellular $\mathrm{TH} 1 / \mathrm{TH} 2$ cytokine production, immunoproliferative T lymphocyte response and natural killer cell activity in newborns, children and adults. Biol. Neonate. 84, 297-303 (2003).

27. Belderbos, M.E. et al. Skewed pattern of Toll-like receptor 4-mediated cytokine production in human neonatal blood: low LPS-induced IL-12p70 and high IL-10 persist throughout the first month of life. Clin. Immunol. 133, 228-237 (2009).

28. Rate, A., Upham, J.W., Bosco, A., McKenna, K.L. \& Holt, P.G. Airway epithelial cells regulate the functional phenotype of locally differentiating dendritic cells: implications for the pathogenesis of infectious and allergic airway disease. J. Immunol. 182, 72-83 (2009). 
29. Maldonado, R.A. \& von Andrian, U.H. How tolerogenic dendritic cells induce regulatory T cells. Adv. Immunol. 108, 111-165 (2010).

30. Wang, Y. \& McCusker, C. Neonatal exposure with LPS and/or allergen prevents experimental allergic airways disease: development of tolerance using environmental antigens. J. Allergy Clin. Immunol. 118, 143-151 (2006).

31. Verhasselt, V. et al. Breast milk-mediated transfer of an antigen induces tolerance and protection from allergic asthma. Nat. Med. 14, 170-175 (2008).

32. Verhasselt, V. Neonatal tolerance under breastfeeding influence. Curr. Opin. Immunol. 22, 623-630 (2010).

33. McCusker, C., Chicoine, M., Hamid, Q. \& Mazer, B. Site-specific sensitization in a murine model of allergic rhinitis: role of the upper airway in lower airways disease. J. Allergy Clin. Immunol. 110, 891-898 (2002).

34. Duan, W., So, T., Mehta, A.K., Choi, H. \& Croft, M. Inducible CD4 + LAP + Foxp3- regulatory T cells suppress allergic inflammation. J. Immunol. 187, 6499-6507 (2011).

35. Le, A.V. \& Broide, D.H. Indoleamine-2,3-dioxygenase modulation of allergic immune responses. Curr. Allergy Asthma Rep. 6, 27-31 (2006).

36. Gordon, J.R., Li, F., Nayyar, A., Xiang, J. \& Zhang, X. CD8 alpha +, but not CD8 alpha-, dendritic cells tolerize Th2 responses via contact-dependent and -independent mechanisms, and reverse airway hyperresponsiveness, Th2, and eosinophil responses in a mouse model of asthma. J. Immunol. 175, 1516-1522 (2005).

37. Patel, B.K., Pierce, J.H. \& LaRochelle, W.J. Regulation of interleukin 4mediated signaling by naturally occurring dominant negative and attenuated forms of human Stat6. Proc. Natl. Acad. Sci. USA 95, 172-177 (1998).

38. Munn, D.H. \& Mellor, A.L. Indoleamine 2,3 dioxygenase and metabolic control of immune responses. Trends Immunol. 34, 137-143 (2013).

39. Hill, M. et al. IDO expands human CD4 + CD25high regulatory T cells by promoting maturation of LPS-treated dendritic cells. Eur. J. Immunol. 37, 3054-3062 (2007).

40. $\mathrm{Li}, \mathrm{X}$. et al. Induction of type $2 \mathrm{~T}$ helper cell allergen tolerance by IL-10-differentiated regulatory dendritic cells. Am. J. Respir. Cell Mol. Biol. 42, 190-199 (2010).

41. Fusaro, A.E. et al. Balance between early life tolerance and sensitization in allergy: dependence on the timing and intensity of prenatal and postnatal allergen exposure of the mother. Immunology 128, e541-e550 (2009).

42. Lisciandro, J.G. et al. Neonatal antigen-presenting cells are functionally more quiescent in children born under traditional compared with modern environmental conditions. J. Allergy Clin. Immunol. 130, 1167-74 e10 (2012).

43. Mosconi, E. et al. Breast milk immune complexes are potent inducers of oral tolerance in neonates and prevent asthma development. Mucosal Immunol 3, 461-474 (2010).

44. Verhasselt, V. Neonatal tolerance under breastfeeding influence: the presence of allergen and transforming growth factor-beta in breast milk protects the progeny from allergic asthma. J. Pediatr. 156, S16-S2O (2010).

45. Lonnqvist, A. et al. Neonatal exposure to staphylococcal superantigen improves induction of oral tolerance in a mouse model of airway allergy. Eur. J. Immunol. 39, 447-456 (2009).

46. Oddy, W.H. et al. TGF-beta in human milk is associated with wheeze in infancy. J. Allergy Clin. Immunol. 112, 723-728 (2003).

47. Oddy, W.H. \& McMahon, R.J. Milk-derived or recombinant transforming growth factor-beta has effects on immunological outcomes: a review of evidence from animal experimental studies. Clin. Exp. Allergy 41, 783-793 (2011).

48. Frischmeyer-Guerrerio, P.A. et al. TGFbeta Receptor Mutations Impose a Strong Predisposition for Human Allergic Disease. Sci. Transl. Med. 5, 195ra94 (2013).

49. Kushwah, R. \& Hu, J. Role of dendritic cells in the induction of regulatory T cells. Cell Biosci. 1, 20 (2011).

50. Lloyd, C.M. \& Hawrylowicz, C.M. Regulatory T cells in asthma. Immunity 31, 438-449 (2009).

51. Nemeth, K. et al. Bone marrow stromal cells use TGF-beta to suppress allergic responses in a mouse model of ragweed-induced asthma. Proc. Natl. Acad. Sci. USA 107, 5652-5657 (2010).

52. Wang, G., Miyahara, Y., Guo, Z., Khattar, M., Stepkowski, S.M. \& Chen, W. "Default" generation of neonatal regulatory Tcells. J. Immunol. 185, 71-78 (2010).

53. Ho, A., Schwarze, S.R., Mermelstein, S.J., Waksman, G. \& Dowdy, S.F. Synthetic protein transduction domains: enhanced transduction potential in vitro and in vivo. Cancer Res. 61, 474-477 (2001). 